\title{
Technology Use and Industrial Transformation: Empirical Perspective
}

\author{
by John R. Baldwin*, Brent Diverty**, and David Sabourin***** \\ Micro-Economics Analysis Division, Statistics Canada
}

No. 75

\section{F0019MPE No. 75 \\ ISSN: 1200-5223 \\ ISBN: 0-662-21731-4}

24A, R.H. Coats Building, Ottawa, K1A 0T6

Facsimile Number: (613) 951-5403

* Phone: (613) 951-8588

Email: BALDJOH@STATCAN.CA

** Phone: (613) 951-5269

*** Phone: (613) 951-3735

\begin{abstract}
August 1995
Presented to the conference entitled "Technology, Information, and Public Policy" at the John Deutsch Institute for the Study of Economic Policy, Queen's University, November 1994.
\end{abstract}

This paper represents the views of the authors and does not necessarily reflect the opinions of Statistics Canada. 


\section{ABSTRACT}

This study examines technology use in Canada's manufacturing sector, and how a set of technology-using manufacturing establishments performed relative to non-users. Data originates from a recent Statistics Canada survey, asking manufacturing firms about their use of 22 advanced manufacturing technologies, and panel data taken from the Census of Manufacturers.

Results show that the use of advanced manufacturing technology is widespread, especially in large firms, that multiple-technology use is the norm, and that technologies are generally combined within, as opposed to across, production stages. The technology revolution has been felt more in the area of inspection and communications, and less in fabrication and assembly. In terms of performance, technology-using establishments pay higher wages, enjoy higher labour productivity, and are gaining market share at the expense of non-users.

Keywords: technology, labour markets, wage rates, competition. 


\section{EXECUTIVE SUMMARY}

Technology Use and Industrial Transformation: Empirical Perspectives outlines how advanced computer-based technologies are transforming the manufacturing sector, and how a set of technology-using establishments have performed relative to non-users.

Results are based on the linkage of a Statistics Canada technology survey to panel data taken from the Census of Manufacturers. This permits an evaluation of the nature of technology use in Canada, as well as a comparison of the market share, productivity, employment share, and wage rates of establishments using, and not using, advanced manufacturing technologies. The findings are:

\section{The extent of technology use in the Canadian Manufacturing Sector}

- Technology use in Canada is widespread, particularly in large firms--advanced manufacturing technology is used in $48 \%$ of manufacturing establishments, accounting for $88 \%$ of manufactured goods.

- Users generally adopt more than one technology. Only 5\% of manufacturers' shipments are produced by single-technology users, while $82 \%$ are produced by multi-technology users, with $56 \%$ being produced by establishments using 5 or more technologies.

- Technology use varies across the six stages of the production process--design and engineering, fabrication and assembly, automated materials handling, inspection and communications, manufacturing information systems, and integration and control.

- The computer-based revolution has been felt more in the area of knowledge acquisition and less in the making, cutting, and assembling process. The most widespread use of technology is in the area of inspection and communications. Some $79 \%$ of shipments originate in establishments using these technologies. The use of fabrication and assembly technologies lags behind, accounting for just $47 \%$ of shipments.

- Even though multiple technology use is the norm, combining technologies across different stages of the production process is not widespread. Generally, establishments combine technologies within one or two specific production stages as opposed to across many, or all, of the stages.

\section{Performance of Technology Users}

- Establishments using advanced technologies in their manufacturing processes gain market share at the expense of non-users. Relative market share grows most rapidly in 
establishments using fabrication and assembly technologies, and those able to effectively combine and integrate technologies at different stages of the production process.

- Technology users enjoy a significant labour productivity advantage over non-users, with the exception of those establishments using fabrication and assembly technologies exclusively. In the 1980's, this advantage grows for all establishments except those using design and engineering technologies. Relative labour productivity grows fastest in those establishments using inspection and communications technologies, and those able to combine and integrate technologies across stages in the production process.

- Technology users offer a higher average wage rate than non-users in 1980, and this differential widens over the decade. The wage rate differential widens the most in establishments whose technologies are associated with the highest initial relative wages. Thus, growing income inequality is associated with patterns of technology use. 


\section{Introduction}

The introduction of the computer into the manufacturing process has ushered in a new industrial revolution. ${ }^{1}$ At the heart of this revolution are advances that have been made in microelectronics. Computers are transforming the technology set and changing the way in which manufacturing establishments do business--by changing the way products are designed and engineered, the cutting and shaping of parts, the assembly process, the planning and control of materials requirements, and the integration of these various processes. Computer-controlled equipment produces goods quickly without sacrificing quality, and offers a wide choice of products, produced exactly as needed. By using computer-based technologies, manufacturers can respond quickly to changes in consumer attitudes and preferences.

The new industrial revolution is associated not just with the spreading use of stand-alone computers, but also with their integration into other goods and their combination with services. Chips and computers are being increasingly imbedded into machines and processes in the industrial system. Once computers were only awkward appendages attached to tools; now they (or more properly, their components like micro-chips) are being integrated into machines. Integration has also occurred because computer-based technology is being bundled with a concept, sold as a service, and integrated into the production process. For example, the materials planning process makes use of computers, but the cost of the computers that are integral to the process makes up a small fraction of total costs. The input into the manufacturing process-materials planning--combines both product and service, and the service costs often far outweigh the cost of the manufactured product.

The spread of computer-based technology has occurred steadily over the last two decades as organizations have incorporated the new technologies into different facets of the production process. Firms have slowly learned how to make use of various computer-related technologies. While the advantages are readily appreciated, difficulties in determining the manner in which organizations can best exploit them have resulted in a slow and uneven adoption rate across the spectrum of commercial technologies that now exist.

Other major transformations of the industrial system have also taken some time. The introduction of electric power sources into the industrial system was spread over three to four decades. Electric motors were first used as stand-alone devices to power machines, then were added on to machines, and finally were directly incorporated into the machines. The census of 1901 first began to measure the horsepower of electric motors, and only 7\% of total horsepower is listed as coming from electric motors in the manufacturing sector in that year. By 1911 this has increased to $20 \%$, to $50 \%$ by 1921 , and to $74 \%$ by 1930 . By the end of the thirties, the census authorities warned that the statistics on electrical horsepower were no longer reliable indicators of motive power because electrical motors had become so integrated into machines that firms had difficulty reporting the electrical horsepower at their command. It is clear, then, that the length of period associated with the introduction of electricity--from the first adoption of the technology to its being largely imbedded into investment goods--took nearly forty years. 
New industrial revolutions proceed slowly because of the large number of complementary goods and services that are required before the technology can find useful applications in a wide range of industries. The correct combination requires considerable trial and error. Mature technologies can be incorporated into the production process with the use of blue prints. When knowledge is readily codified and transferred, diffusion is quite rapid. By way of contrast, the introduction of new technologies during the early phases of an industrial transformation is more akin to prototype construction. Plans are still used, but the final product often diverges from the initial specifications. Progress in the early phase of the new industrial transformation requires flexible adoption. Search takes place through a learning-by-experimentation process.

During the transformation period, solutions that make use of the new technologies are only gradually incorporated into the production process. Which experiments will turn out to be successes, and which are destined to become failures, is often an enigma. As such it is sometimes difficult to see the shape that the industrial transformation is taking.

This paper provides such an evaluation for one particular industrial sector--manufacturing. Because of long-standing interest in this sector, taxonomies have been developed to measure computer-based advanced technology usage. Surveys have been taken of technology use employing these taxonomies. We can therefore depict the pattern that is being followed by the latest technological revolution. By linking the surveys to longitudinal data on the performance of survey respondents, we can also begin to evaluate the effect that technological adoption is having on industry participants.

\section{Classification of Advanced Manufacturing Technologies (AMTs)}

Computer-based technologies have penetrated all parts of the production process. Computer-aided design and engineering is used in the early stages. Numerically controlled (or computer numerically controlled) machines are part of the cutting and assembly process. Computers aid the communication and inspection process either by providing information through local area networks (LANs) or through computers on the factory floor. Computers are also basic to materials planning systems. While computers have stimulated the development of individual components of the production process, they are also central to those systems that bring the components together into one integrated whole.

\subsection{Functional Groups}

Information about the use of 22 advanced manufacturing technologies is available from the Survey of Manufacturing Technology (SMT) that was conducted by Statistics Canada in March 1989. The survey asked establishments in the manufacturing sector to indicate their use, planned

use, or non-use of 22 separate advanced technologies. ${ }^{3}$ All of these new technologies are the result of applying the computer to various facets of the production process. 
To examine how the use of advanced manufacturing technologies differs across stages of the production process, the 22 technologies considered here are classified into 6 functional groups (Table 1). The functional categories are: design and engineering, fabrication and assembly, automated materials handling systems, inspection and communications, manufacturing information systems, and integration and control.

There are three technologies in the design and engineering group. Computer-aided design (CAD) and engineering (CAE) uses the computer to design and test parts or products. Computer-aided manufacturing (CAM) utilizes $\mathrm{CAD}$ output to control machines used in the manufacturing of the part or product. Digital representation of CAD output is used to control machines used in manufacturing parts or products.

Table 1

Advanced Manufacturing Technologies by Functional Group

Functional Group

Design and Engineering

Fabrication and Assembly
Manufacturing Information Systems Integration and Control

\section{Technology}

Computer-aided design and engineering (CAD/CAE)

CAD output to control manufacturing machines

(CAD/CAM)

Digital representation of CAD output

Flexible manufacturing cells/systems (FMC/FMS)

Numerically Controlled (NC) Machines

Computer Numerically Controlled (CNC) Machines

Materials Working Lasers

Pick \& Place Robots

Other Robots

Automated Storage/Retrieval Systems (AS/RS)

Automated Guided Vehicle Systems (AGVS)

Automatic Inspection Equipment - Inputs

Automatic Inspection Equipment - Final Products

Local Area Network for Technical Data

Local Area Network for Factory Use

Inter-Company Computer Network (ICCN)

Programmable Controllers

Computers used for control in factories

Materials Requirement Planning (MRP)

Manufacturing Resource Planning (MRP II)

Computer Integrated Manufacturing (CIM)

Supervisory Control \& Data Acquisition (SCADA)

Artificial Intelligence/Expert Systems (AI) 
The fabrication and assembly group consists of five technologies. Flexible manufacturing systems (FMS) are machines controlled by computers or programmable controllers, which have fully integrated material handling capabilities able to accept raw materials and deliver finished products. Computer numerically controlled (CNC) machines are controlled by a computer imbedded in the machine. Materials working laser(s) are used for welding, cutting, scribing, and marking. Pick and place robots transfer items by means of point-to-point moves. "Other" robots are used to perform repetitive tasks like cutting, welding, drilling, or painting through specific, programmed motions.

Automated materials handling systems include automated storage and retrieval systems (AS/RS) and automated guided vehicle systems (AGVS). AS/RS use computer-operated equipment for the handling and storage of parts, materials, goods-in-progress, and finished goods. AGVS are vehicles equipped with computer-controlled automatic guidance devices, capable of transporting parts, materials, goods-in-progress, and finished goods between points on the factory floor.

The inspection and communications group is made up of two inspection and five communication technologies. Inspection technology consists of automated sensor-based equipment, able to test both incoming materials and outgoing final goods to ensure they meet specifications. Communications technologies include local area computer networks (LANs), to exchange technical information between different points in the production process, wide area and inter-company computer networks to link plants to subcontractors, suppliers, and/or customers, and programmable controllers, which are solid state industrial control devices capable of being programmed to perform switching functions.

A sub-group of the previous set of technologies consists of automatic control devices. It is comprised of the two "factory floor" technologies from the inspection and communications group-- programmable controllers and stand-alone computers used for control on the factory floor.

Manufacturing information systems include materials requirements planning (MRP), and manufacturing resource planning (MRP II). MRP uses the computer to keep track of orders, inventories, and finished goods. MRP II uses the computer to manage the loading and use of machines, as well as inventory control and material handling.

The final group, integration and control, consists of sophisticated technologies designed to integrate the various production stages through the computer. Included in this group are computer integrated manufacturing (CIM), a totally automated factory where all processes are integrated and controlled by a central computer, supervisory control and data acquisition (SCADA), which involves "real-time" monitoring and control of production processes, and artificial intelligence, which is the ability of machines to learn from experience and perform tasks usually attributed to human intelligence. 


\subsection{Combinations of Functional Groups}

In addition to examining the penetration of individual technologies within functional categories, we shall also consider how establishments combine technologies across groups. For this study, three combinations of functional groups will be used to explore the nature of the complementarity of technologies across functional groups.

The first combines technologies used in design and engineering, fabrication and assembly, inspection and communications, manufacturing information systems, and integration and control-all the functional groups with the exception of automated material handling technologies. This mix of functional groups represents comprehensive technology use in a fully integrated factory. Automated material handling has been excluded because it has by far the lowest adoption rate of the six functional groups (20.9\%), suggesting that it involves highly specialized technologies which are not applicable to, or compatible with, most production processes, and should not be included in a measure of comprehensive technology use.

The second combination is similar to the first, except that integration and control has been omitted. This combination represents comprehensive technology use which is not fully integrated.

The third combination represents the use of technologies focused on the factory floor production process, within a fully integrated factory. These include technologies from the fabrication and assembly, automatic control device (the sub-group of inspection and communications which is comprised of programmable controllers and in-factory computers for control), and integration and control groups.

\subsection{Technology Groups}

Taking the six individual functional groups and the three combinations of functional groups together yields a set of nine technology groups for study. When the terms functional group or combination are used explicitly, they refer only to that particular subset of the technology groups.

\section{Extent of Technology Use in Canada}

The pattern of technology use can be described as extensive, intensive, or comprehensive. Extensive use represents the degree to which establishments employ more than one advanced technology, regardless of the functional group to which it belongs. Intensive use is the degree of technology adoption at the level of the functional group--design and engineering, fabrication and assembly, inspection and communications, automated material handling, manufacturing information systems, and integration and control--or at the level of the individual technology. 
Finally, comprehensive technology use measures the extent to which at least one technology from each of several functional groups is employed--the three combinations.

Two different weighting strategies (shipment and establishment weights) are used in this study. Weighting in accordance with shipment value establishes a link between the use of technology and the economic contribution of establishments, giving greater importance to establishments of larger size. Weighting in terms of the number of establishments does not distinguish between establishments of different economic weight, and indicates only the extent to which technology use is widespread among manufacturing plants in Canada. In what follows, the shipment-weighted adoption rates are emphasized.

\subsection{Use of Advanced Manufacturing Technologies (Extensive Use)}

Advanced technologies are used extensively in the Canadian manufacturing sector. Almost half (48\%) of manufacturing establishments use at least one advanced manufacturing technology. However, when the economic weight of the users is considered, it is apparent that the new industrial revolution touches, in some form, most of the production of the manufacturing sector. Some $88 \%$ of shipments are produced in establishments that use at least one of the advanced manufacturing technologies (Table 2). Moreover, multiple technology use is the norm. A mere $5 \%$ of shipments are produced by single-technology users compared to $56 \%$ for establishments using at least 5 technologies.

Table 2

Adoption Rate by Number of Technologies, 1989

Number of

Technologies
Adoption Rate

(\% of Establishments)
Adoption Rate

(\% of Shipments)

$\begin{array}{lrr}0 & 52 & 12 \\ 1 & 12 & 5 \\ 2 \text { to } 4 & 22 & 26 \\ 5 \text { to } 9 & 11 & 33 \\ 10 \text { or more } & 3 & 23 \\ \text { At least } 1 & 48 & 88\end{array}$

\subsection{Technology Use Within Functional Groups (Intensive Use)}

While advanced manufacturing technologies have come to affect most output, their use varies considerably across functional groups. The intensity of technology use within functional 
groups is summarized in Table 3 (Rows 1 to 7). The establishment-weighted adoption rate of a functional group is the percentage of establishments that use at least one technology from the particular group in question. The shipment-weighted adoption rate measures the percentage of shipments produced by technology users, and approximates the relative market share of technology users employing at least one technology within a particular functional group. Nontechnology users are those establishments that do not use any technologies within the functional group, although they may use the technologies of other groups.

The functional group with the highest shipment-weighted adoption rate is inspection and communications (group 4). Some $79.0 \%$ of shipments in 1989 come from establishments using technologies from the inspection and communications group. The high adoption rate attributed to this particular group of technologies is due mainly to the use of automatic control devices-programmable controllers and stand-alone computers used for control on the factory floor--the sub-group of the inspection and communications class (group 4A, see Table 3), whose shipmentweighted adoption rate is $67.1 \%$.

Table 3

Adoption Rate by Technology Group, 1989

\begin{tabular}{lccc}
\hline Technology Group & $\begin{array}{c}\text { Group } \\
\text { Number }\end{array}$ & $\begin{array}{c}\text { Adoption Rate } \\
\text { (\% of Establishments) }\end{array}$ & $\begin{array}{c}\text { Adoption Rate } \\
\text { (\% of Shipments) }\end{array}$ \\
\hline Design and Engineering & 1 & 19.2 & 52.1 \\
Fabrication and Assembly & 2 & 21.0 & 46.7 \\
Automated Materials Handling Systems & 3 & 6.0 & 18.4 \\
Inspection and Communications & 4 & 32.9 & 79.0 \\
Automatic Control Devices & $4 \mathrm{~A}$ & 20.9 & 67.1 \\
Manufacturing Info Systems & 5 & 18.4 & 51.2 \\
Integration and Control & 6 & 9.4 & 39.8 \\
Combination 1 & $\mathrm{C} 1$ & 1.5 & 14.9 \\
Combination 2 & $\mathrm{C} 2$ & 4.4 & 22.8 \\
Combination 3 & $\mathrm{C} 3$ & 2.8 & 23.3 \\
\hline
\end{tabular}

The inspection and communications group is followed by design and engineering $(52.1 \%)$, manufacturing information systems (51.2\%), fabrication and assembly (46.7\%), integration and control (39.8\%), and automated materials handling systems (18.4\%). While the computer-based revolution is often described in terms of its effects on fabrication and assembly, its greatest impact so far has been in the area of inspection and communications. Computers provide knowledge; the application of that knowledge to the actual fabrication and assembly process has been 
somewhat slower. Pulling the various processes together via integration and control technologies is even less common.

\subsection{Technology Use Across Functional Groups (Comprehensive Use)}

Extensive technology use does not translate into comprehensive use--adoption rates for the combinations of functional groups are low (Table 3, Rows 8, 9, and 10). Combination 1 (comprehensive technology use within a fully integrated factory) has a shipment-weighted adoption rate of only $14.9 \%$. Combination 2 (comprehensive technology use without integration) has an adoption rate only slightly higher--22.8\%. Combination 3 (production-based use within a fully integrated factory) has the highest adoption rate of the three combinations, but still only accounts for $23.3 \%$ of shipments. Even though multiple technology use is the norm, combining technologies across functional groups is uncommon. Generally, establishments adopt technologies specific to one or two functional groups.

\subsection{Patterns Of Use Within Functional Classes}

Since technologies are not generally combined across functional groups but multiple technology use is the norm, technologies within the same functional groups tend to be combined. Whether adoption rates are relatively uniform between technologies of the same functional groups is examined here.

Table 4 summarizes the adoption rates of individual technologies. Only the design and engineering functional group is dominated by a single technology--CAD/CAE has an adoption rate of $49 \%$, at least two and a half times higher than the two other technologies in this group. In all other functional groups, the adoption rates are more evenly distributed. The best example of this is found in the inspection and communications group, where five of the seven technologies have adoption rates between $31 \%$ and $41 \%$.

\subsection{Summary}

To summarize, the computer has changed many aspects of the manufacturing process. Cheap processing power, large storage capacities, and efficient networking capabilities have allowed both large and small establishments to join this revolution. Inspection and communications is the functional group most affected by these changes, containing six of the 10 most used technologies. The success of the inspection and communications group, as a whole, is due to the relatively high adoption rates of each of the technologies belonging to this group, rather than to the dominance of one technology (see Table 4).

In contrast, the use of sophisticated advanced technologies in the fabrication and assembly process has progressed less quickly. Moreover, few establishments combine several technologies 
from different functional groups. Partly because of this lack of breadth, few establishments use integrative technologies. The computer-based revolution, then, has mainly occurred in the area of knowledge acquisition. Computers have been put to work acquiring, digesting, and disseminating information. They are not yet making, cutting, and assembling on the same scale.

\section{Table 4}

\section{Adoption Rate by Individual Technology, 1989}

\begin{tabular}{|c|c|c|c|}
\hline $\begin{array}{l}\text { Functional } \\
\text { Group }\end{array}$ & Technology & $\begin{array}{l}\text { Adoption Rate } \\
\text { (Percent of } \\
\text { Establishments) }\end{array}$ & $\begin{array}{c}\text { Adoption Rate } \\
\text { (Percent of } \\
\text { Shipments) }\end{array}$ \\
\hline \multirow[t]{3}{*}{1} & $\mathrm{CAD} / \mathrm{CAE}$ & 16.9 & 49.0 \\
\hline & CAD/CAM & 6.7 & 20.1 \\
\hline & Digital representation of CAD output & 4.0 & 12.7 \\
\hline \multirow[t]{5}{*}{2} & Flexible manufacturing cells/systems & 7.2 & 20.6 \\
\hline & Numerically controlled machines & 14.1 & 29.6 \\
\hline & Materials working lasers & 2.0 & 9.3 \\
\hline & Pick and place robots & 3.4 & 14.9 \\
\hline & Other robots & 2.9 & 15.6 \\
\hline \multirow[t]{2}{*}{3} & Automated storage and retrieval systems & 4.3 & 14.7 \\
\hline & Automated guided vehicle systems & 2.4 & 9.2 \\
\hline \multirow[t]{7}{*}{4} & Auto inspection equipment for inputs & 8.9 & 30.7 \\
\hline & Auto inspection equipment for final products & 8.4 & 34.9 \\
\hline & LAN for technical data & 11.6 & 40.8 \\
\hline & LAN for factory use & 9.3 & 36.7 \\
\hline & Inter-company computer networks & 10.4 & 35.4 \\
\hline & Programmable Controllers & 17.8 & 63.6 \\
\hline & Computers used for control on the factory floor & 11.7 & 49.9 \\
\hline \multirow[t]{2}{*}{5} & Materials requirement planning & 17.5 & 48.6 \\
\hline & Materials resource planning & 10.2 & 33.0 \\
\hline \multirow[t]{3}{*}{6} & Computer integrated manufacturing & 4.4 & 21.1 \\
\hline & Supervisory control and data acquisition & 6.5 & 33.9 \\
\hline & Artificial intelligence and expert systems & 1.6 & 6.5 \\
\hline
\end{tabular}

\section{Performance Indicators}

While the SMT survey data can tell us where advanced manufacturing technologies have made the most progress, they alone cannot describe the effect on an establishment of using them. 
Establishments adopting technologies need to be tracked and compared to those not using technologies.

In order to follow the progress of technology users, the 1989 technology survey is linked to longitudinal panel data back to 1980 , taken from the Census of Manufacturers. ${ }^{4}$ This panel of some 4,200 plants is treated as a study group for purposes of analysis. The study group accounts for some $10 \%$ of the population but $50 \%$ of total shipments in the universe, and therefore represents primarily large plants.

Treating the panel as a study group means we are interested only in the experience of this large group of observations--a group which covers the large plant population in a comprehensive fashion. We do not extrapolate the experience of this group to the population here, because to do so would mean expanding coverage to an additional 30,000, mainly small, plants with different technology usage rates. In a later section, however, we do perform this exercise and provide population estimates.

The study group is divided into technology users and non-users on the basis of their answers to the 1989 survey. The market ${ }^{5}$ and employment shares for technology users and nonusers in the sample are calculated for each of the intervening years back to 1980. In addition, the income of production workers and productivity per worker are calculated for each of these two groups.

Changes in market share reveals the extent to which technology use has increased--both because technology users grow more rapidly than non-users, and because more establishments have become users. Changes in relative labour productivity, employment share, and relative wage rates demonstrate the effect of advanced manufacturing technologies on the input mix. Changes in relative labour productivity can stem from higher skill requirements associated with the new technology, or from increases in capital-labour intensity brought about by the adoption of new technology. Changes in employment share are the net result of market-share and labourproductivity growth. Changes in relative wages may be the result of changes in the demand for skilled labour, increases in productivity, or an increase in the complexity of products or production processes.

Technology use for this exercise is defined as the adoption of at least one technology from a technology group--design and engineering, fabrication and assembly, automated materials handling systems, inspection and communications, manufacturing information systems, and integration and control, or one of the combinations defined previously. We are interested in differences in the patterns of change in the relative market share, wage rate, employment share, and labour productivity across different technologies. This technique does not control for technology use across categories except through the combinations defined previously. We are interested, for example, in whether establishments using design and engineering technologies do better as a whole, not whether they do better when combined with a particular communications technology. 


\subsection{Market-Share Growth}

The market-share analysis proceeds in two stages. In the first stage, the market share of users and non-users is calculated for manufacturing as a whole. Market-share growth here is the joint result of users doing better than non-users in a particular industry and of those industries where technology use is higher gaining in size relative to others. We then ask whether the same phenomenon exists when market shares are calculated at a finer industry classification level. Relative labour productivity, employment share, and wage-rate measures will be treated in the same manner.

Since the information on technology use is taken only from the 1989 survey, there will be some error in classification in earlier years that makes our test only a weak one of the growth of advanced technology use. Establishments that were non-users in 1989 were very likely to have been non-users earlier; but establishments that were users of advanced technologies in 1989 were not necessarily users earlier in the decade. Hence the aggregate market share of technology users is biased upwards in earlier years because technology users in 1989 who may not have been so in 1980 are included as users for the entire period. This bias is gradually reduced over time until it reaches zero in 1989. Consequently, growth of the aggregate market share of technology users is biased downward.

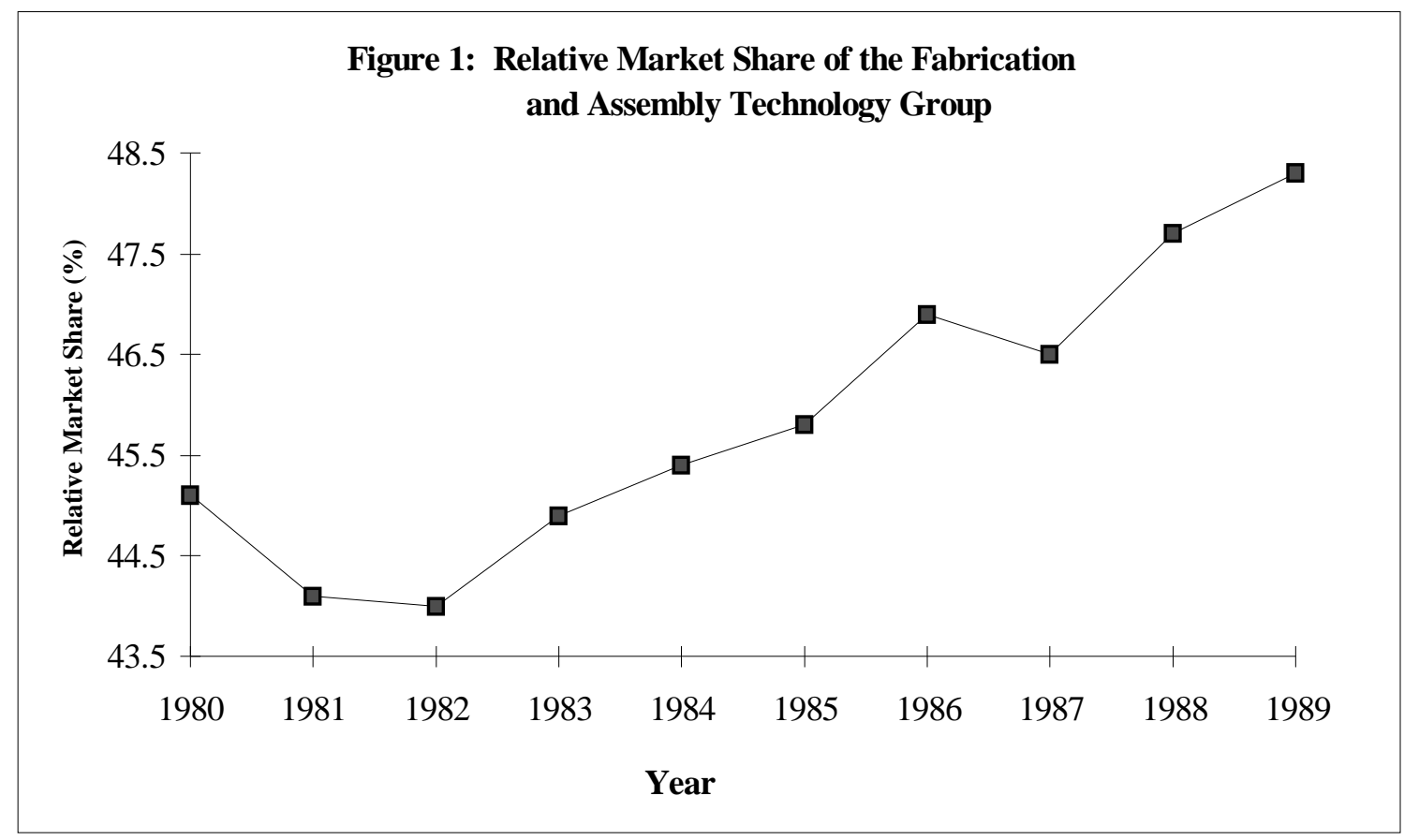

In technology groups where a sufficient number of technology users in 1989 were nonusers in 1980, and where non-use results in significant market-share loss, the market share of our "technology-using" group will fall before it rises. The market-share curves of these technology 
groups will be S-shaped--initially negatively sloped reflecting the inclusion of shrinking nontechnology users, then positively sloped as non-users become users, and finally exhibiting diminishing growth as adoption rates approach a ceiling. This pattern of market-share growth is found in the fabrication and assembly group (Figure 1). The design and engineering group and all three combinations are also characterized by similar curves, all of which reach their lowest point in 1982. Market-share growth rates will, therefore, be calculated using 1982 as the base year. Even so, there is still likely to be a downward bias in the market-share growth rates that are reported here.

\subsubsection{Market-Share Growth By Technology Group, National Level}

Technology users in all functional groups have gained market share at the expense of non-users (Table 5). Establishments using advanced manufacturing technologies are supplanting those who do not. The size of the market-share growth rate ${ }^{6}$ of users varies across groups, but is everywhere positive (Table 5 and Figure 2). It is highest for users of fabrication and assembly technologies $(10.0 \%)$. No other individual functional group has a growth rate even half as large. Fabrication and assembly is followed by manufacturing information systems (3.2\%), inspection and communications (2.9\%), design and engineering (2.2\%), automated materials handling systems $(2.0 \%)$, and integration and control $(0.2 \%)$.

Table 5

Relative Market Share of Technology Users (Shipment weighted)

\begin{tabular}{lcccc}
\hline Technology Group & $\begin{array}{c}\text { Group } \\
\text { Number }\end{array}$ & $\begin{array}{c}\text { Relative } \\
\text { Market Share } \\
\mathbf{1 9 8 2}(\boldsymbol{\%})\end{array}$ & $\begin{array}{c}\text { Relative } \\
\text { Market Share } \\
\mathbf{1 9 8 9}(\boldsymbol{\%})\end{array}$ & $\begin{array}{c}\text { Market-Share } \\
\text { Growth Rate } \\
(\boldsymbol{\%})\end{array}$ \\
\hline & & & & \\
Design and Engineering & 1 & 55.0 & 56.2 & 2.2 \\
Fabrication and Assembly & 2 & 44.0 & 48.3 & 10.0 \\
Automated Materials Handling Systems & 3 & 20.1 & 20.5 & 2.0 \\
Inspection and Communications & 4 & 79.2 & 81.4 & 2.9 \\
Automatic Control Devices & $4 \mathrm{~A}$ & 69.7 & 70.9 & 1.8 \\
Manufacturing Info Systems & 5 & 51.8 & 53.5 & 3.2 \\
Integration and Control & 6 & 45.8 & 45.9 & 0.2 \\
Combination 1 & $\mathrm{C} 1$ & 16.9 & 18.7 & 10.7 \\
Combination 2 & $\mathrm{C} 2$ & 23.3 & 26.1 & 12.3 \\
Combination 3 & $\mathrm{C} 3$ & 23.9 & 27.6 & 15.3 \\
& & & & \\
\hline
\end{tabular}


All three combinations are characterized by higher rates of market-share growth than any of the functional groups. Combination 1 (comprehensive technology use with integration) grows at a rate of $10.7 \%$ over the ten-year period. The comprehensive but non-integrated group, combination 2 , shows a slightly higher growth rate of $12.3 \%$. The highest rate of growth $(15.3 \%)$ occurs for combination 3, integrated factory-floor technologies (fabrication and assembly, automatic control devices, and integration and control technologies).

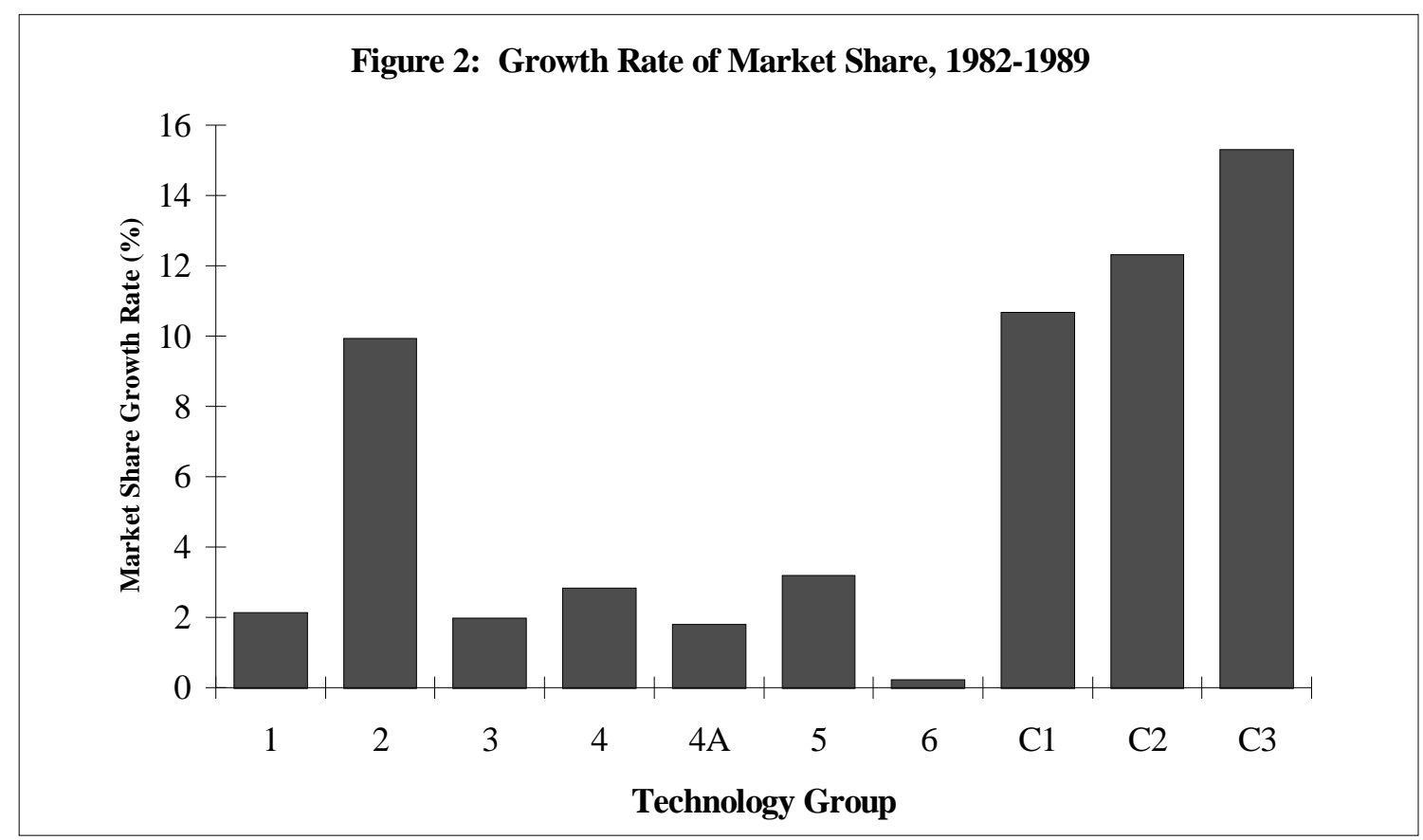

(Note: the median rate of growth is significantly greater than zero for each technology group)

The highest market-share growth rate is associated with the broad integration of technologies from multiple functional groupings. The fabrication and assembly functional group (group 2) may have the highest rate of growth of the individual groups (10.0\%), but combining it with technologies from certain other functional groups increases the growth rate compared to that found for technologies taken from fabrication and assembly alone. When fabrication technologies are combined with automatic control devices and integration technologies (combination 3), users achieve the highest growth rate $(15.3 \%)$. Therefore, the technologies that best complement fabrication and assembly technologies are to be found in related technology groups. Furthermore, comprehensive use which includes fabrication and assembly technologies, whether integrated (combination 1) or not (combination 2), also improves market-share growth over fabrication and assembly technologies used alone. Thus, establishments that have been able to combine technologies across functional groups in an effective fashion have had the fastest market-share growth.

While the rate of change of relative market share is useful in understanding how rapidly 
market share has changed within a technology group, using it to compare growth rates between functional groups tells only part of the story if the base-year adoption rates differ. An alternate success standard for comparisons across technology groups is the percentage point change in market share (the difference between the 1982 and 1989 market shares).

Using this criterion, fabrication and assembly is still the individual functional group with the largest market-share increase (4.4 percentage points), but it now ranks higher than any of the combinations, as well. Combination 3 is second at 3.7 percentage points, followed by combination 2 at 2.9 percentage points. The inspection and communications group increases its relative importance and is next, with a 2.3 percentage point change in relative market share. It now ranks above combination 1, at 1.8 percentage points. The other groups--manufacturing information systems at 1.7, design and engineering at 1.2, automated materials handling systems at 0.4 , and integration and control at 0.1 percentage points--still experience the slowest growth.

\subsubsection{Market-Share Growth by Technology Group, Industry Level}

That technology users have increased their market share may be the result of changes in the industrial structure. Industries that are not amenable to AMT use may have been in decline over the 1980s. To investigate the extent to which this was the case, market shares of technology and non-technology users are calculated at the two-digit industry level. This allows us to investigate whether gains in market share for technology users are the norm across industries. We also ask whether there are some industries in which advanced technologies appear to have had little effect. This is done by investigating whether there are some industries where advanced technology use has resulted in little or no market-share gain.

To do so, market-share growth rates are examined from two perspectives (Table 6). First, industry market-share growth rates within technology groups are compared across industries to determine whether success is widespread, or limited to a small number of industries. Second, data on market-share growth rates by industry across technology groups are investigated to determine whether, in particular industries, there are competitive advantages conferred upon establishments for most of the types of advanced technology options investigated here.

Of the 15 industries, increases in market share are enjoyed by at least 10 in each of the functional groups. Establishments using fabrication and assembly technologies gained market share in 12 of the 15 industry classifications. Close behind are integration and control, manufacturing information systems, and inspection and communications groups, each with 11. Design and engineering and automated materials handling systems each have ten industries gaining market share at the expense of non-using establishments. Market-share growth, due to technology use within a functional group, is to be found in most industries.

Market-share growth is less prevalent at the industry level for the technology combinations, especially when the technologies are integrated. Some 11 industries are characterized by growing market shares in establishments using comprehensive but non-integrated 
technologies (Combination 2). This falls to 10 industries for those establishments using integrated production-based technologies (Combination 3). The number of industries experiencing a marketshare gain from comprehensive and integrated technology use (Combination 1) is just 8. While national data indicate that the relative market share is growing fastest for establishments able to overcome the barriers associated with combining technologies across functional groups, these combinations are advantageous only in certain industries.

\section{Table 6}

Sign of Market-Share Percentage Point Change by Industry, for the Technology Groups (shipment weighted)

\begin{tabular}{|c|c|c|c|c|c|c|c|c|c|c|}
\hline \multirow[b]{2}{*}{ Industry } & \multirow[b]{2}{*}{1} & \multicolumn{7}{|c|}{ Technology Group } & \multirow[b]{2}{*}{$\mathrm{C2}$} & \multirow[b]{2}{*}{ C3 } \\
\hline & & 2 & 3 & 4 & $4 \mathrm{~A}$ & 5 & 6 & C1 & & \\
\hline $\begin{array}{l}\text { Food, Beverage, } \\
\text { and Tobacco }\end{array}$ & + & - & - & + & + & + & ++ & + & + & + \\
\hline Rubber and Plastics & - & + & - & - & - & - & - & - & - & + \\
\hline $\begin{array}{l}\text { Leather, Textile, } \\
\text { and Clothing }\end{array}$ & ++ & ++ & + & + & + & + & + & + & ++ & + \\
\hline Wood & - & + & - & + & + & - & + & - & - & + \\
\hline $\begin{array}{l}\text { Furniture and } \\
\text { Fixtures }\end{array}$ & + & ++ & + & ++ & ++ & ++ & + & + & ++ & + \\
\hline $\begin{array}{l}\text { Paper and Allied } \\
\text { Products }\end{array}$ & + & + & + & + & + & + & + & - & + & + \\
\hline $\begin{array}{l}\text { Printing and } \\
\text { Publishing }\end{array}$ & + & + & + & - & + & - & + & + & + & - \\
\hline Primary Metals & + & + & + & + & + & + & + & + & + & + \\
\hline $\begin{array}{l}\text { Fabricated Metal } \\
\text { Products }\end{array}$ & - & -- & + & - & - & + & + & + & + & - \\
\hline Machinery & ++ & ++ & + & ++ & ++ & ++ & ++ & ++ & ++ & + \\
\hline $\begin{array}{l}\text { Transportation } \\
\text { Equipment }\end{array}$ & - & - & - & - & - & + & - & - & - & - \\
\hline $\begin{array}{l}\text { Electrical and } \\
\text { Electronic Products }\end{array}$ & + & + & ++ & + & + & + & + & - & - & + \\
\hline $\begin{array}{l}\text { Non-metallic } \\
\text { Mineral Products }\end{array}$ & + & + & - & + & + & - & - & - & + & - \\
\hline $\begin{array}{l}\text { Petroleum and } \\
\text { Chemical Products }\end{array}$ & - & + & + & + & + & + & - & - & + & - \\
\hline $\begin{array}{l}\text { Other } \\
\text { Manufacturing } \\
\text { Industries }\end{array}$ & ++ & ++ & + & ++ & ++ & ++ & + & + & ++ & + \\
\hline National Level & 1.2 & 4.4 & 0.4 & 2.3 & 1.3 & 1.7 & 0.1 & 1.8 & 2.9 & 3.7 \\
\hline
\end{tabular}

++ percentage point change $\geq 5.0 \quad-$ percentage point change $\leq-5.0$

$+\quad 0<$ percentage point change $<5.0 \quad-\quad \mathbf{5 . 0}<$ percentage point change $<0$ 
In some industries, few technologies are associated with market-share gain. For others, gains from technology use are realized for most of the technologies dealt with here. Technologyusing establishments in the leather, textile, and clothing, furniture, primary metal, machinery, and miscellaneous manufacturing industries generally gain market share. This is not the case for rubber and plastics, and transportation equipment.

\subsection{Relative Labour Productivity}

Changes in market share result from inherent benefits associated with technology use--the development of new, improved, less expensive or more reliable products. That success is also accompanied, or caused by, changes on the input side that are manifested in changes in the relative labour productivity, employment share, and relative wage rates of technology users.

The increased labour productivity that occurs in establishments using advanced technologies may result from the need for increasingly skilled workers to operate and/or service the new technology, or from an increase in the capital-labour ratio. These are direct results of the use of advanced technologies. Increased labour productivity may also be the result of organizational change, emphasis on total quality management, and the use of "work teams"-practices that have recently been implemented in an attempt to cut costs and improve productivity. The latter are indirectly related to the use of advanced technologies. Generally, changes in labour productivity that are associated with new technology use occur because superior establishments make correct decisions in several different areas simultaneously (Baldwin and Johnson, 1994a).

\subsubsection{Relative Productivity Growth By Technology Group, National Level}

In order to examine changes in relative labour productivity, the ratio of output per production worker for technology users to non-users over the period 1980 through $1989^{8}$ is calculated. Technology use is based on the same categories that were employed for the marketshare analysis.

Since technology use is based on the 1989 survey, this index provides a weak test of the change that occurs in technology users relative to non-users. Some establishments classified as users based on 1989 evidence will be non-users earlier in the period. Evidence of this is to be found in the shape of the relative labour productivity index for the fabrication and assembly, comprehensive and integrated technology (combination 1), and comprehensive but non-integrated technology (combination 2) groups. All of these have S-shaped relative labour productivity growth curves similar to those exhibited for relative market shares. The difference is that the curves "bottom out" in 1981 instead of 1982. Thus, labour productivity gains lead market-share gains. Cost advantages resulting from increased productivity per worker are eventually passed on to consumers in the form of lower prices, and translate into increases in market share, with a lag. 
For the purpose of our comparison, therefore, gains in labour productivity will be measured over the period 1981 to 1989.

With the exception of the fabrication and assembly group, technology users enjoy a significant labour productivity advantage over non-users (Table 7). ${ }^{9}$ Establishments with the largest advantages are those using technologies from the inspection and communications category. Their labour productivity is 1.73 times that of establishments not using any inspection or communications technologies. The use of other technologies is also associated with significant advantages. Workers in establishments using technologies from the integration and control group are 1.67 times more productive, automated materials handling systems 1.52 times more productive, combination 1--comprehensive and integrated use--is 1.47 times more productive, and combination 3--integrated production process use--is 1.45 times more productive. Establishments having less of a labour productivity advantage are those using manufacturing information systems (1.27 times more productive), design and engineering (1.18 times more productive), and combination 2--comprehensive but non-integrated use--(1.15 times more productive). Surprisingly, establishments using technologies in fabrication and assembly do not have a labour productivity advantage over non-technology users. Fabrication and assembly also has one of the lowest adoption rates.

Table 7

Relative Productivity of Technology Users (Shipment Weighted)

\section{Technology Group}

\section{Group} Number

\section{Relative} Productivity 1981
Relative Productivity 1989

$\begin{array}{lrll}\text { Design and Engineering } & 1 & 1.21(0.032) & 1.18(0.010) \\ \text { Fabrication and Assembly } & 2 & 0.87(0.016) & 1.0(0.019) \\ \text { Automated Materials Handling Systems } & 3 & 1.35(0.140) & 1.52(0.097) \\ \text { Inspection and Communications } & 4 & 1.50(0.016) & 1.73(0.012) \\ \text { Automatic Control Devices } & 4 \mathrm{~A} & 1.45(0.007) & 1.51(0.043) \\ \text { Manufacturing Info Systems } & 5 & 1.16(0.029) & 1.27(0.015) \\ \text { Integration and Control } & 6 & 1.62(0.090) & 1.67(0.045) \\ \text { Combination 1 } & \mathrm{C} 1 & 1.28(0.145) & 1.47(0.114) \\ \text { Combination 2 } & \mathrm{C} 2 & 1.04(0.080) & 1.15(0.069) \\ \text { Combination 3 } & \mathrm{C} 3 & 1.20(0.090) & 1.45(0.076)\end{array}$

(note: standard errors are in parenthesis)

Combining technologies from different functional groups is associated with strong labour productivity advantages. However, productivity per worker in combination 1 (comprehensive technology use with integration) is greater than combination 2 (comprehensive technology use 
without integration). Thus, for comprehensive technology use, the most significant labour productivity advantages are achieved when the entire process is integrated. There is other evidence that supports the importance of integration in some circumstances. Used alone, fabrication and assembly technologies are not associated with a productivity advantage; but combining them with automatic control devices and integration technologies (combination 3) results in a significant labour productivity advantage.

The relative productivity-per-worker advantage enjoyed by technology-using establishments grew over the period of study (Figure 3). Users in all technology groups, with the exception of design and engineering and integration and control, have experienced significantly positive growth rates of relative productivity. Combination 3--integrated production process use-has the highest growth rate of relative productivity over the eighties $(21 \%)$, followed by inspection and communications (15.8\%), combination 1--comprehensive integrated technology use--(15.1\%), fabrication and assembly (14.0\%), automated materials handling systems (12.4\%), combination 2--comprehensive but non-integrated technology use--(10.5\%), and manufacturing information systems $(10.0 \%)$. Hence, establishments generally increase their labour productivity advantage over time, as they become more familiar with the capabilities of their chosen technology sets.

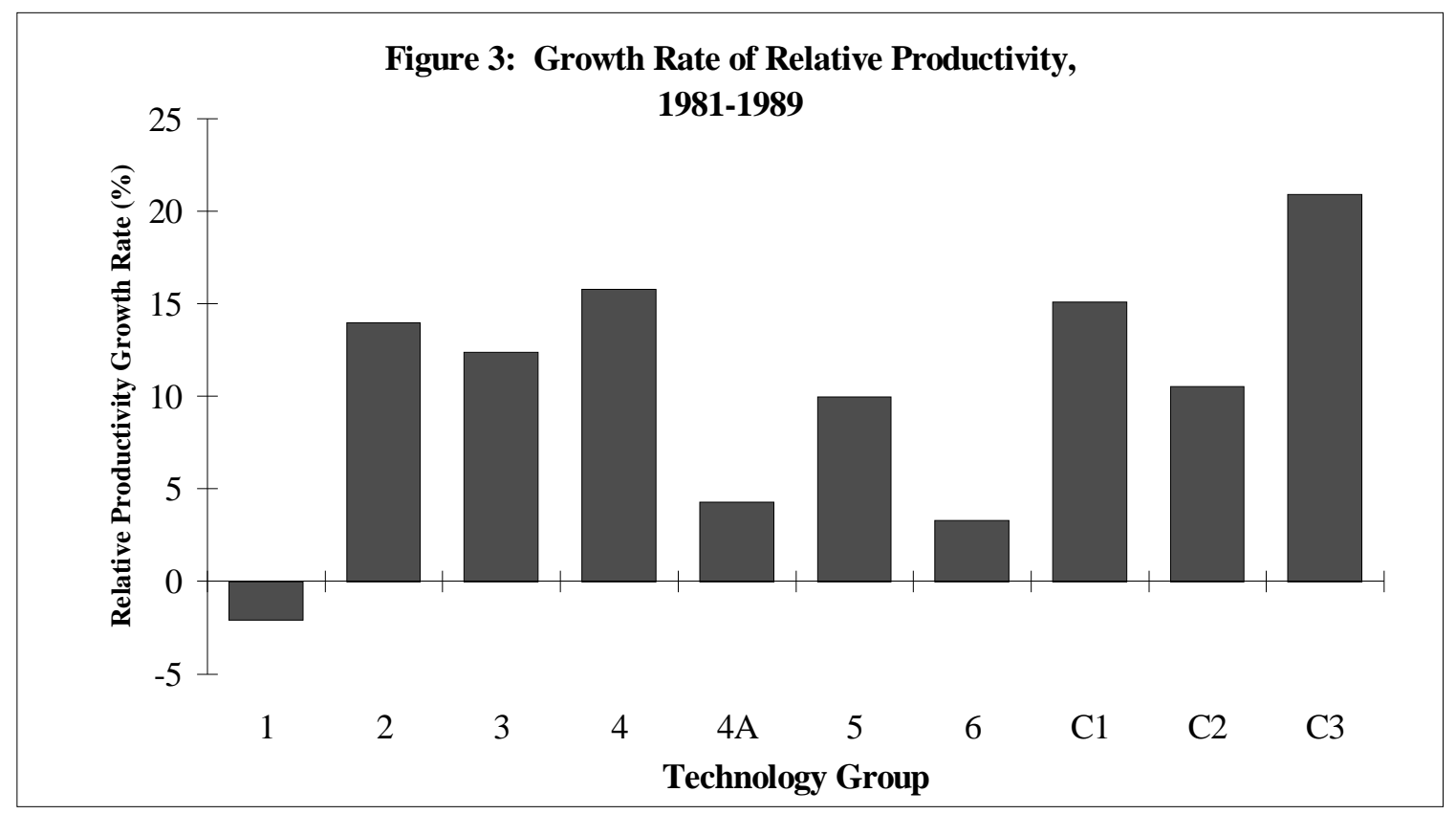

(note: growth rates are significantly different from zero at the 5\% level, with the exception of groups 1 and 6 )

Still, it is apparent that comprehensive use is not always associated with a productivity performance which is superior to intensive use. For example, even though inspection and communications is the functional group with the highest rate of productivity growth $(15.8 \%)$, when combined with technologies from other groups (groups 1, 2, 5, and 6 in combination 1, or 
groups 1,2 , and 5 in combination 2$)$, the productivity growth rate actually falls $(15.1 \%$ for combination 1, $10.5 \%$ for combination 2). Conversely, when inspection and communications technologies are combined with technologies from fabrication and assembly and automatic control devices, users achieve the highest relative productivity growth rate, $21 \%$ over the 10 year period.

Similarly, establishments using fabrication and assembly technologies do better when they also use technologies from the integration and control category. Used alone, fabrication and assembly technologies have a productivity growth rate of $14 \%$ over the decade. In combinations that include both fabrication and assembly and integration and control technologies, the growth rate increases to $15 \%$ for combination 1 and $21 \%$ for combination 3 . The growth rate falls, however, to $10.5 \%$ for combination 2 , which includes fabrication and assembly but not integration and control technologies.

Establishments whose technology use is characterized by combination 3--the integrated production-process technology group--have the highest relative productivity growth rate (21\%). They also achieve the highest market-share growth rate of any technology group. This suggests that the greatest benefits, in terms of market share and productivity growth, accrue to establishments managing to solve the puzzle of implementing advanced computer-based technologies on the shop floor.

\subsection{Employment Share and Relative Wage Rates}

The use of technology in manufacturing, and its success or failure as measured by relative market share and productivity growth, impacts directly and indirectly on the share of employment attributed to, and the relative wage rate paid by, technology-using firms. The next three sections attempt to establish a relationship, at the national and industry level, between successful technology implementation and these two inputs into the manufacturing process.

\subsubsection{Employment Share}

On average, technology-using establishments have gained market share at the expense of non-users, and have increased their labour productivity advantage. How this affects the relative employment share of technology users is not immediately clear. Relative labour productivity and market share have offsetting effects on the relative employment share. Ceteris paribus, increases in market-share will increase output, the demand for workers, and employment; whereas, increases in labour productivity will decrease the demand for workers and employment at the current level of output. To investigate the net impact of these two forces, the shares of production workers employed by technology users relative to non-users is calculated.

The percentage point change in the employment and market shares of technology users

over the period 1982-1989 is presented in Figure 4, by technology group. On average, the change in employment share is lower than the change in market share because of gains in relative labour 
productivity. The impression of weak employment share gains is borne out by examination of the industry results. Only in two technology groups--design and engineering, and fabrication and assembly--are employment share gains positive at the national level and in the majority of industries. Elsewhere, small positive gains in inspection and communications, manufacturing information systems, and combinations 1 and 2 at the national level do not translate into employment share growth in a majority of industries. ${ }^{10}$

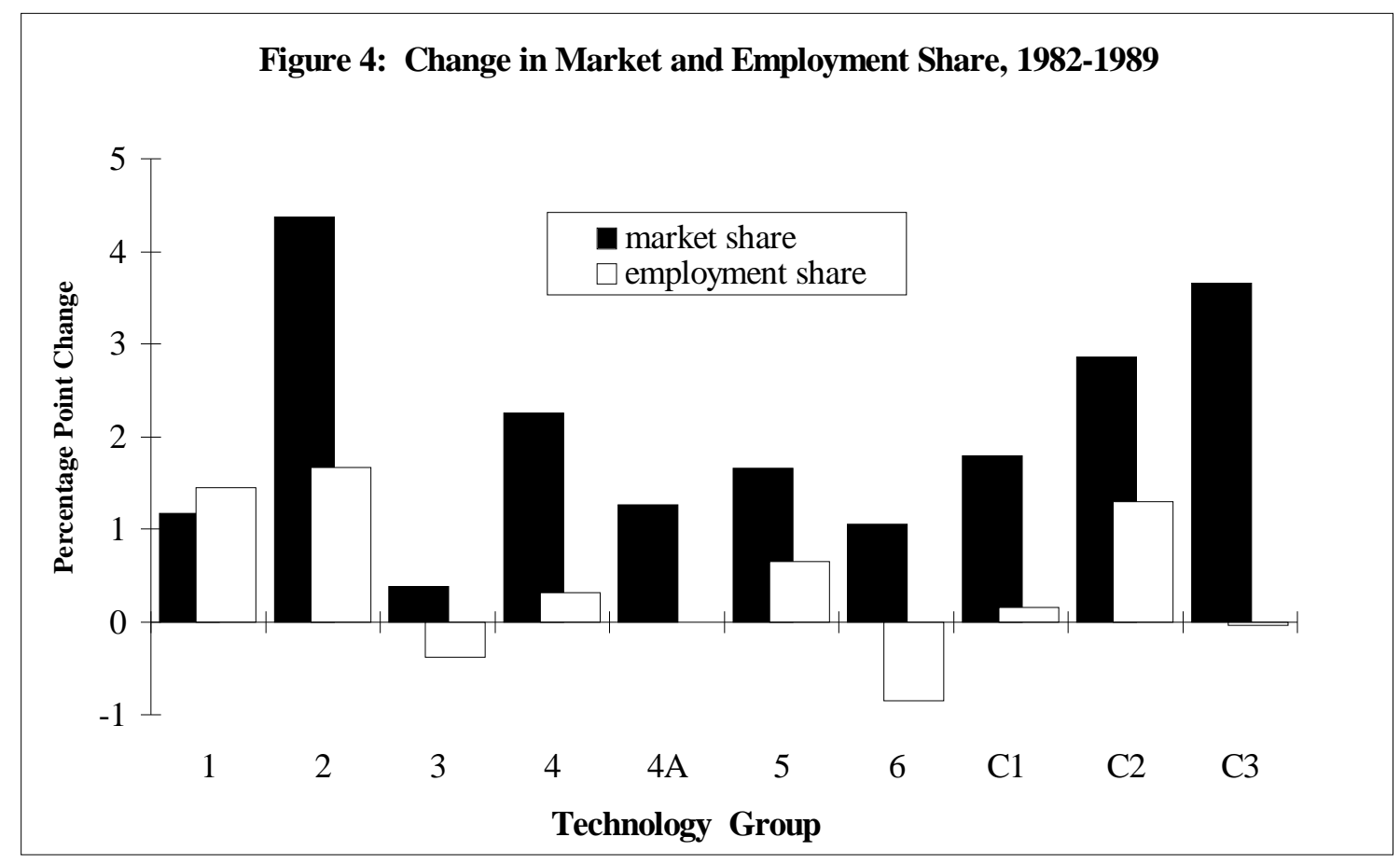

\subsubsection{Growth in Relative Wage Rates By Technology Group, National Level}

To investigate the effects of technology adoption on the relative wage rates paid by technology-using establishments, income per production worker in technology-using establishments is compared to income per production worker in non-technology-using establishments for the period 1980 through $1989 .{ }^{11}$ Contrary to the other two measures, this index has increased continually from the beginning of the period, therefore no end-point adjustments are required. For comparability to the relative productivity index, however, 1981 is used as the base year for the relative wage-rate index.

Establishments using advanced manufacturing technologies pay significantly higher wages than non-technology-using establishments for all technology groups in both 1981 and 1989 (Table 8). ${ }^{12}$ In 1989, establishments using technologies from the inspection and communications group pay the highest relative wage rate, 1.31 times the rate for non-users. Integration and control is second (1.28 times), followed by combination 1 (1.27 times), combination 3 (1.26 times), 
combination 2, automated materials handling, and design and engineering (each 1.17 times), fabrication and assembly (1.12 times), and manufacturing information systems (1.10 times). Thus, workers in technology-using establishments earn more per year, on average, than their counterparts in non-technology-using establishments.

An explanation for the wage-rate differential between users and non-users may be that establishments adopting increasingly complex technologies must pay higher wages to attract workers with the appropriate skill levels. This hypothesis is supported by a US study which found that the higher wages paid, on average, by technologically advanced plants can be explained by the higher skill level of their employees (Doms, Dunne, and Troske, 1994). Certainly, the wage rate paid by an establishment is related to its productivity. A Spearman correlation test of the data used here shows that relative wage rates are positively correlated with relative productivity across technology groups, and this relationship grows stronger over the decade. Hence, the use of advanced manufacturing technologies is associated with higher skilled, higher paid, and more productive workers, as compared to non-technology users.

In addition to the disparity between wage rates paid by users and non-users, there also exists a wage-rate disparity within the set of technology-using firms. The functional groups can be differentiated by the degree to which they are directly imbedded in the production process or serve to manage it via diagnostics, monitoring, and quality control. The former are involved directly in the creation of production; the latter enhance management productivity. ${ }^{13}$ We refer to those functional groups containing imbedded technologies as "blue collar" and those containing production management technologies as "white collar."

Table 8

\section{Relative Wage Rates of Technology Users (Shipment Weighted)}

\begin{tabular}{lccc}
\hline \multicolumn{1}{c}{ Technology Group } & $\begin{array}{c}\text { Group } \\
\text { Number }\end{array}$ & $\begin{array}{c}\text { Relative Wage } \\
\text { Rate 1981 }\end{array}$ & $\begin{array}{c}\text { Relative Wage } \\
\text { Rate 1989 }\end{array}$ \\
\hline Design and Engineering & 1 & $1.14(0.008)$ & $1.17(0.005)$ \\
Fabrication and Assembly & 2 & $1.08(0.006)$ & $1.12(0.006)$ \\
Automated Materials Handling Systems & 3 & $1.14(0.024)$ & $1.17(0.038)$ \\
Inspection and Communications & 4 & $1.21(0.002)$ & $1.31(0.002)$ \\
Automatic Control Devices & $4 \mathrm{~A}$ & $1.18(0.002)$ & $1.25(0.005)$ \\
Manufacturing Info Systems & 5 & $1.06(0.006)$ & $1.10(0.007)$ \\
Integration and Control & 6 & $1.19(0.014)$ & $1.28(0.013)$ \\
Combination 1 & $\mathrm{C} 1$ & $1.21(0.034)$ & $1.27(0.035)$ \\
Combination 2 & $\mathrm{C} 2$ & $1.14(0.023)$ & $1.17(0.027)$ \\
Combination 3 & $\mathrm{C} 3$ & $1.16(0.025)$ & $1.26(0.024)$ \\
& & & \\
\hline
\end{tabular}

(note: standard errors are in parenthesis) 
The highest relative wages are paid, both at the beginning and the end of the period, by those establishments using "white-collar" technologies (i.e. inspection and communications). Relative wages in the "blue-collar" technology-using establishments (i.e. fabrication and assembly) are among the lowest. Furthermore, this disparity is growing--across technology groups, relative wage-rate growth over the period 1981-89 is positively correlated with the 1981 relative wage rate. Figure 5 shows that wage-rate growth in the "blue-collar" fabrication and assembly group is $4 \%$ but relative wage-rate growth is closer to $8 \%$ in the "white-collar" inspection and communications group.

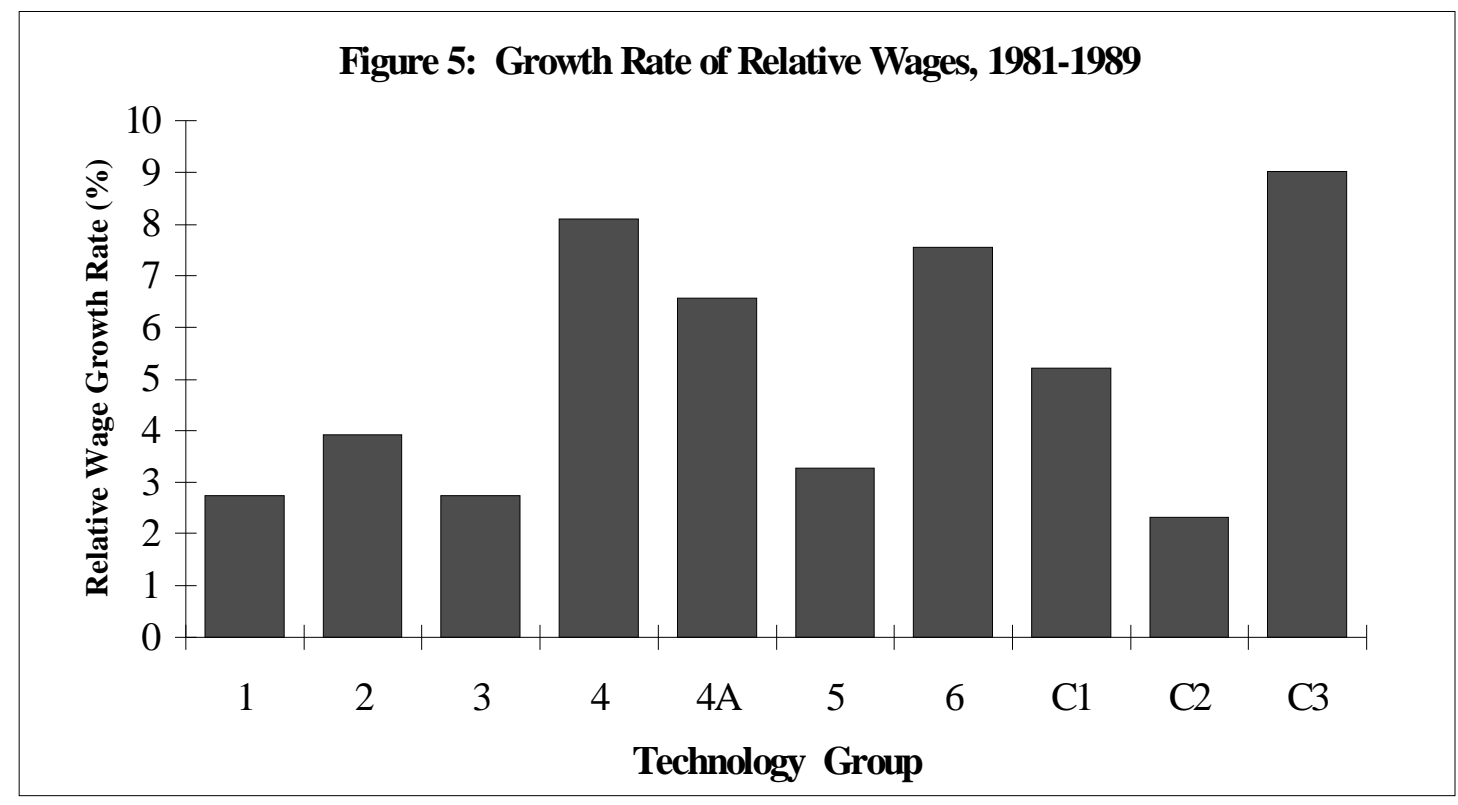

(note: growth rates significantly greater than zero at the 5\% level, using a one-tailed t-test)

\subsubsection{Industry Level}

National averages show increases in relative wage-rates in all technology groups. To investigate whether this holds across industries, relative wage rates for technology users are calculated at the two-digit industry level.

Excluding the seldom used automated materials handling category, relative wage rates increase in at least 11 of the 15 two-digit industries in each individual functional group. The national results for the various combinations of technologies do not generalize as easily. They are the result of strong relative-wage increases in a small subset of industries, especially for combination 1 where only 6 out of 15 industries experienced relative-wage increases. Combinations 2 and 3 have increases in 10 and 11 industries, respectively. These results broadly reflect those for market-share gain at the industry level. 


\section{Population Estimates: The Effect of Adding Small Firms}

An alternate method of examining the effects of technology adoption is to use the sample of establishments to infer changes that have occurred in the population. This can be done using the sampling weights derived from the 1989 survey. This section explores the results of using the 4,000 observations in the study group to infer changes that occurred in the population of some 40,000 manufacturing establishments. Results for the population will differ from those of the study group to the extent that small and large plants experience different effects from the use of advanced technology. The study group consists predominantly of large establishments while the population consists primarily of small establishments.

When results are calculated for the population, ${ }^{14}$ it is still the case that advanced technology users experience gains in market share, relative productivity and relative income per production worker. There are, however, some interesting changes in the relative size and rate of change across technology groups, that show that the success of small firms stems more from the use of individual functional group technologies than from integrated combinations. In comparison with the study group results, market-share growth rates in the population are significantly higher in all individual functional groups, while slightly lower in two of the three combinations (Figure 6). Since small plants are more likely to use advanced technologies in only one area of the production process while larger plants are more likely to combine technologies across groups, and since the study group used previously in this study heavily weights large plants, the use of population data assigns greater importance to functional group use and less importance to combinations. Population data suggests that high rates of market-share growth are associated with a broader set of technology options than is the case with the study group.

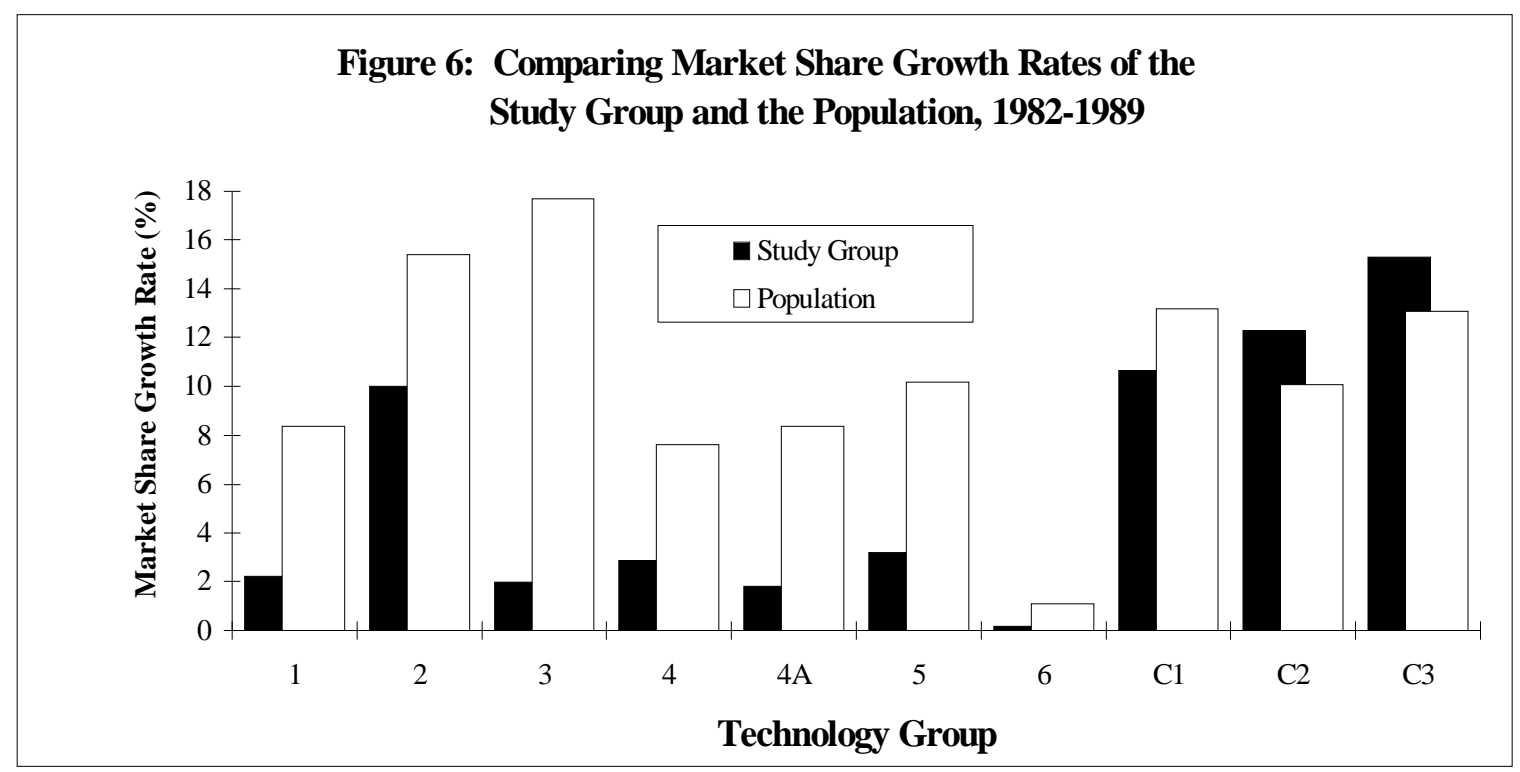


Population estimates of the productivity advantage of technology-using firms produce very few changes. Compared to the study group, the growth rates of labour productivity in "white collar" functional groups, like inspection and communications, increase; the productivity growth rates of "blue collar" functional groups, like fabrication and assembly, decline, but are still positive. Finally, integration becomes even more important to success than was found previously.

When population data are used, changes in employment share are larger in eight of the ten technology groups (Figure 7). Increases are particularly large in the functional groups, where market share gains are the largest. The difference between the results for the study group and the population strongly suggest that employment gains are coming in smaller, rather than larger, plants-- a finding compatible with the research reported in Baldwin and Picot (1994).

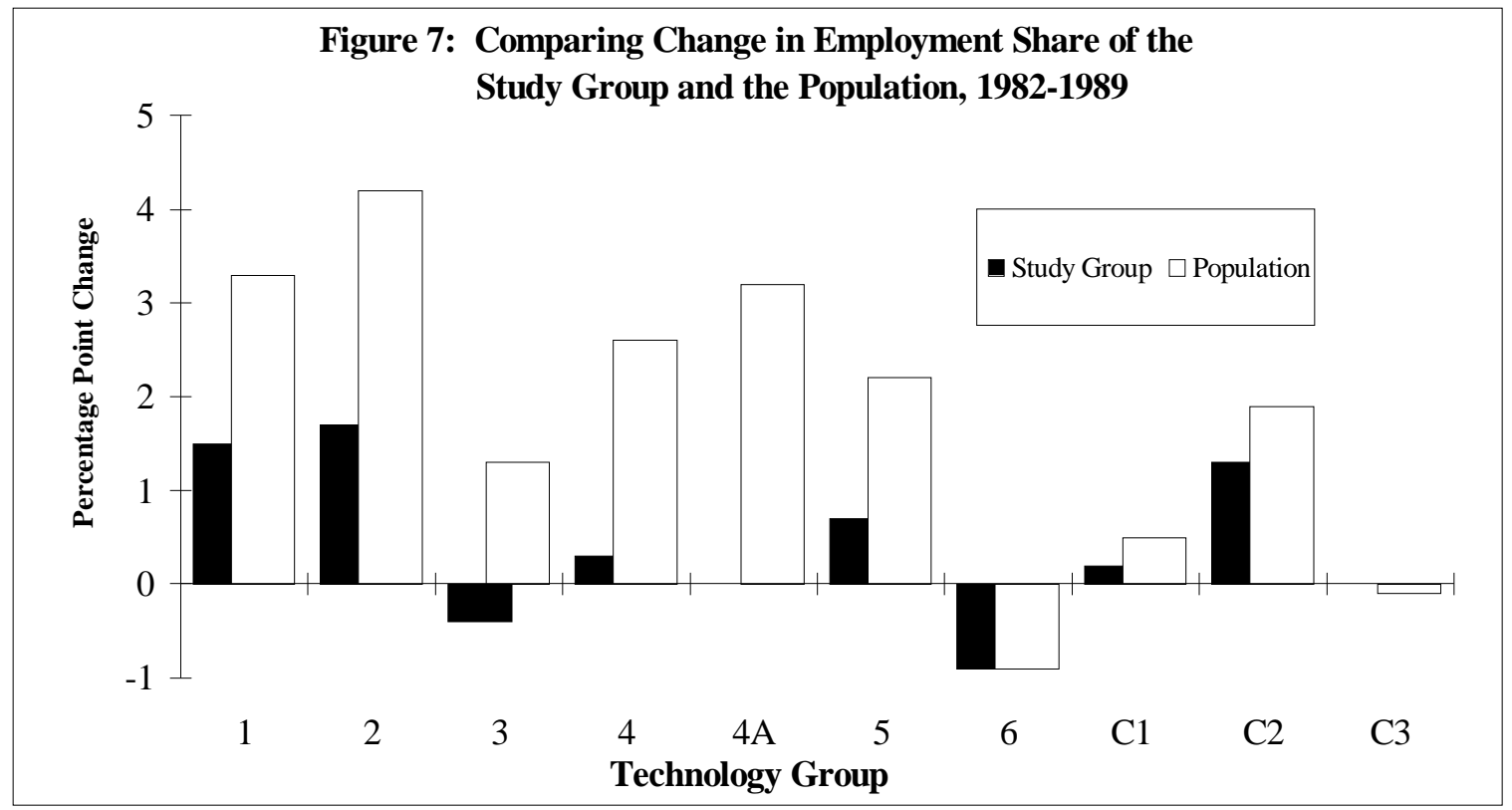

\section{Conclusion}

It is clear that the inspection and communications group, and in particular its control function, is where computer-based technologies have made the greatest impact. More establishments adopt technologies from inspection and communications than any other technology group. Irrespective of whether the study-group or population estimates are used, establishments using inspection and communications technologies have the highest relative market share and labour productivity ratio, and one of the highest relative wage rates compared to users of technologies from other functional groups. Inspection and communications technologies are critical to success when combining technologies across functional groups. Further, the relative labour productivity and wage rates of establishments using inspection and communications technologies are growing faster than elsewhere. 
The adoption of inspection and communications technologies has had widespread effects on the firm, including changes in organizational structure. The development of communications and control technologies has dramatically reduced the costs of acquiring and utilizing information. Communications technologies facilitate the collection of information. Control technologies allow that information to be used to manage processes, but only if the information can be digested. Successful adoption of these technologies into the production process has required new techniques to filter and digest the information.

Old structures, not meant to filter constantly changing and expanding information, have had to be modified. As a result, changes in management structure have eliminated many middle management positions. Individuals who performed routine information collection--collection which is now better done by machine--are no longer needed. Machines can filter information, repackage it and send it directly to senior management without the need for human intervention by middle managers. Computers collect information and pass it along more quickly, and in more variants, than human intervention could previously accomplish.

Communications and control systems have also replaced routinized decision-making where decisions could be readily codified. Decisions on warehousing and inventory planning are now handled on a routine basis by computer-based planning systems. These and other management information systems often provide the first applications of artificial intelligence systems--making decisions that change as information is fed into the process and that lead the machine to change the decision rule as well.

At the same time as some managers are being replaced, the functions of the remaining managers are changing. They have moved from basic filtering and monitoring functions (machines now do this) to searching for new ways to put the machines to use. Accompanying this development are further changes in organizational structure. Flexible organizational structures, new work arrangements, and empowerment are several of the means by which firms attempt to find ways to allow employees to respond to the increases in information that have been generated by these new communications and control technologies. The "new organization" of work encourages employees to participate in improving the company's position--from the factory floor, to the R\&D shop, to management. This is made possible by the emergence of computers that facilitate the "flow of information" between all parts of the organization as well as with customers and suppliers.

Training has also become important in those firms that are generally the most technologically advanced (see Baldwin and Johnson, 1994b). Some of this is aimed at teaching specific skills, but much of this is aimed at enhancing the ability of both managers and production workers to process signals and to react to them.

Total quality management programs have also evolved as firms find additional uses for the new information that the communications and control technologies provide. Additional information means that monitoring programs are far more detailed than in the past. This in turn has led to a substantial improvement in quality control. Increased monitoring is allowing 
substantial reductions in the rejection rate of particular products. More importantly, quality control is being extended to encompass the concept of total quality management, through certification of stages in the production process. This is a technique involving the codification of rules, allowing managers to standardize the processes of monitoring and control. It establishes benchmarks against which success can be measured at the establishment level. The fact that certification programs in the area of total quality management have developed to their present advanced status shows the dramatic effects and relative maturity of communications and control technologies.

Another outgrowth of the information explosion associated with the communications and control revolution is the stress that has been placed on bench-marking as a firm strategy. Benchmarking is a type of quality control, based on the performance of state-of-the art competitors. Like total quality management, it requires large bodies of information to be digested, indexed, categorized, and given a priority. To be done well, it has to be integrated into a firms' management information system. Once more, computer-based technologies are essential for the development of this strategy.

In contrast to communications and control functions, the computer revolution has had less of an effect on the factory floor. Fabrication and assembly has one of the lowest adoption rates of all the functional groups. It is surpassed by those in inspection and communications, design and engineering, and manufacturing information systems. Considerable progress remains before the futuristic depiction of the factory floor production process (where machines control machines, where robots replace people) is a widespread phenomenon. It is, however, the case that success in small plants, both in terms of market share and employment gains, is closely associated with the use of advanced fabrication and assembly technology.

Another area that lags is the use of integration and control technologies, with an adoption rate just behind that of fabrication and assembly. However, establishments using these technologies have been growing more rapidly when combined with fabrication and assembly technologies and automatic control devices (Combination 3). These establishments also have one of the highest rates of increase in relative labour productivity and wages.

Use of integration is low because comprehensive technology is not widely used. It is rare to find each of several functional technologies--design, fabrication, inspection, and manufacturing information systems--used in one establishment. Some of this may simply arise because smaller establishments specialize in less than a full range of activities, but this is probably not the most important explanation. Rather, like integration and control, meshing the separate facets of the new computer technologies is difficult. Mastering the adoption of a diverse set of new opportunities takes time.

The adoption of both communications and fabrication technologies have high payoffs. Both are associated with significant market share and labour productivity gains; however, inspection and communications technologies have already spread throughout the system, while fabrication and assembly technologies have not yet experienced the same diffusion. This difference is 
probably related to the size of the market and the degree of specialization permitted in terms of third-party services. Communications problems are common to different firms and processes, and specialized firms have evolved to solve these problems. Competition in this sector is intense. Even where solutions have to be tailored to individual needs, knowledge from outside the organization can be easily imported to produce a solution. Diffusion proceeds rapidly here.

By way of contrast, the successful incorporation of advanced computer-related technologies into the production process is more idiosyncratic. Production processes differ across industries (and even within industries because of plant-size differences). Specific technology adaptation for fabrication technologies has to be done more frequently at the level of the firm. The knowledge that is required for successful operation may also be of the type that is not readily transferred, because the development of this knowledge requires experimentation with the unique production processes of individual firms. This is especially the case with integrated systems that involve fabrication and assembly. The spread of a technology is slower here because of the inherent problems associated with the knowledge transfer of highly specific information.

In the future, we should expect to find continuing changes in the fabrication and assembly stage as the highly specific production problems of each firm are gradually resolved by a workforce that becomes increasingly familiar with solutions that have worked previously in different, but related, situations. Networking and the cooperation of firms within clusters--that Von Hippel (1988) has described--should contribute to the increase in applications in this area. This is not to say that the information revolution is over in areas of established technologies. New applications will continue to be developed, and the declining cost of computer power will facilitate experiments aimed at developing new methods of acquiring, organizing, and analyzing information.

One final area where the effects of advanced technologies have also been felt is wage structures. In recent years, inequality in the distribution of earnings has widened. Debate has revolved around the sources of this change. Evidence on relative wage rates presented here suggests that the earnings distribution is broadly related to technology use. Establishments with advanced manufacturing technologies pay higher wages than those without. Moreover, the wage rate differential has grown fastest in those technology groups where relative wages were initially greatest. More evidence is required before the full effects of the technology revolution on wages can be fully estimated, but the results presented here are suggestive of the direction that the research can pursue. 


\section{NOTES}

1. See the Economist (1994).

2. For the US experience, see David (1990).

3. The survey is based on a representative sample of establishments in the Canadian manufacturing sector. There are 4,200 establishments in the sample, of which 3,952, or $94 \%$, responded

4. The sample of establishments asked to complete the 1989 SMT is based on a 1985 frame. Linking the SMT to panel data for the period 1980-89 means that the sample includes neither the deaths between 1980 and 1985 nor the births between 1985 and 1989. Thus, the amount of share change will be understated since some deaths of non-users and some births of users have been excluded. The reader should consider this paper to be a summary of what happens in what is essentially a panel of continuing establishments. Corrections which we have made for under-reported births and deaths (not reported here) substantially strengthen the story that market-share gains are associated with technology use.

5. These market shares are not to be confused with the population estimates presented in the previous section. The shares here refer just to the panel of 4,200 establishments that are linked to the 1989 survey.

6. Growth rates are calculated by dividing the difference between the two end-point years by the base year.

7. If we treat the study group as a sample, standard statistical tests can be used. To examine the significance of the market-share growth rates, non-parametric tests are used. They confirm that the median rate of market share growth in every category is significantly greater than zero.

8. Output per worker for a technology group is calculated as the sum of all output divided by the sum of all workers, which is equivalent to the employment-weighted average of output per worker.

9. Using a two-tailed t-test, the relative productivity measures of all technology groups are significantly different from one.

10. These results say nothing about the effects of relative market share and productivity on overall levels of employment. Employment rates cannot be inferred from the rate of change of employment share, since even where the share of employment is decreasing over time, overall employment may be increasing in an industry or economy that is growing. 
11. Income per worker for a technology group is calculated as total production-worker wages divided by total production workers in that group, which is just the employment-weighted average wage.

12. Using a two-tailed t-test, the relative wage rate measures of all technology groups are significantly different from one.

13. For a broader, but related classification, see Strassmann (1990).

14. For this we use the 1989 probability weights attached to the 1989 survey. 


\section{REFERENCE}

Baldwin, J.R. and Johnson (1994a). "Business Strategies in Innovative and Non-Innovative Firms in Canada", Research Paper \#73, Analytical Studies Division, Statistics Canada.

Baldwin, J.R. and Johnson (1994b). "Human Capital Development and Innovation: The Case of Training in Small- and Medium-Sized Enterprises", Research Paper \#74, Analytical Studies Division, Statistics Canada.

Baldwin, J.R. and G. Picot (1994), «Employment Generation by Small Producers in the Canadian Manufacturing Sector», Research Paper \#70, Analytical Studies Division, Statistics Canada.

David, Paul (1990), "The Dynamo and the Computer", American Economic Review, Papers and Proceedings.

Doms, M. and T. Dunne and K. Troske (1994), «Workers, Wages, and Technology», mimeo Center for Economic Studies, U.S. Census Bureau.

The Economist (1994), "A Survey of Manufacturing Technology", Mar. 5, pp.2-18.

Fortier, Y. and L.M. Ducharme and F. Gault (1993), "A Comparison of the Use of Advanced Manufacturing Technologies in Canada and the United States",STI Review, No. 12, pp.81-100.

National Research Council, Corporate Planning and Evaluation (April, 1994), National Systems of Innovation: A Research Paper on Innovation and Innovation Systems in Canada .

Northcott, J. and G. Vickery (1993), "Surveys of the Diffusion of Microelectronics and Advanced Manufacturing Technology",STI Review, No.12, pp.7-35.

Strassmann, P.A. (1990), The Business Value of Computers, Connecticut: Information Economic Press

Vickery, G. and D. Campbell (1989), "Advanced Manufacturing Technology and the Organization of Work", STI Review, No.6, pp.105-146.

Von Hippel, E. (1988), The Sources of Innovation. Oxford: Oxford University Press. 